\title{
$\begin{array}{ll}\text { Research Square } & \text { Preprints are preliminary reports that have not undergone peer review. } \\ \text { They should not be considered conclusive, used to inform clinical practice, }\end{array}$
}

\section{Erenumab safety and efficacy in migraine: a systematic review and meta- analysis of randomized clinical trials}

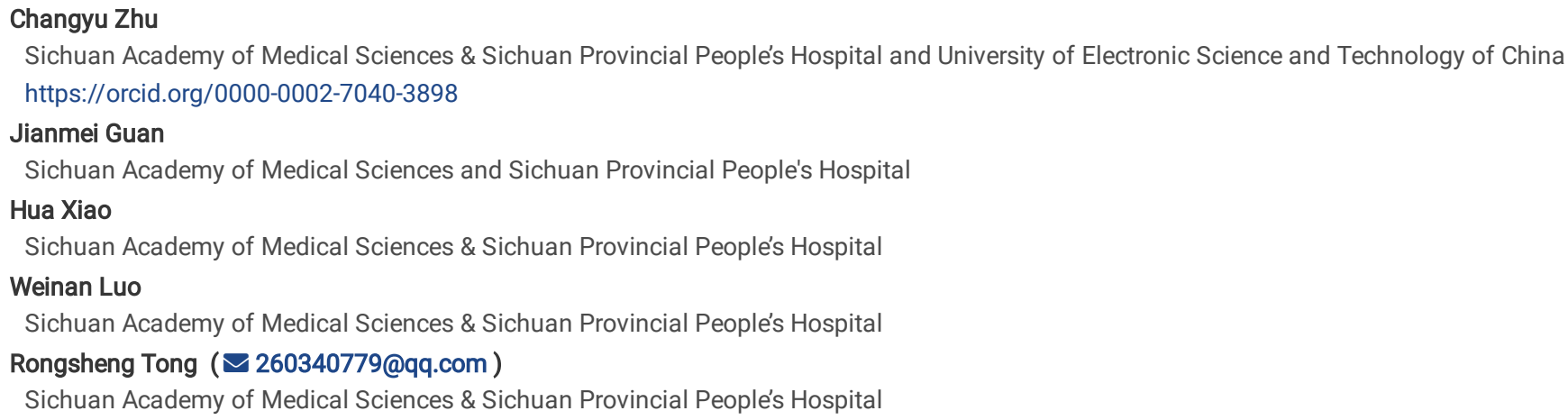

Version of Record: A version of this preprint was published at Medicine on December 1st, 2019. See the published version at https://doi.org/10.1097/MD.0000000000018483. 


\section{Abstract}

Background: Erenumab is a new medicine approved lately in the US for the preventive treatment of migraine in adults. We aimed to conduct a meta-analysis to evaluate the efficacy and safety of erenumab in patients with migraine.

Methods: The electronic database composed of PubMed, Embase and Cochrane library was independently retrieved by two reviewers. Only randomized controlled trials (RCTs) that compared between placebo and erenumab were included in this analysis. mean differences (MDs) and Pooled risk ratios (RRs) as well as their corresponding $95 \%$ confidence intervals (Cls) were calculated for continuous and dichotomous data, respectively.

Results: Total five RCTs representing 2928 patients were included. Pooled analysis showed significant reductions of the $50 \%$ reduction(RR 1.55 ; $95 \% \mathrm{Cl}, 1.35$ to $1.77 ; \mathrm{P}<0.00001 ; \mathrm{I}^{2}=49 \%$ ). In addition, the mean monthly migraine days (MMMDs) from baseline in the erenumab group compared with placebo (MD -1.32 , $95 \% \mathrm{Cl},-1.73$ to $-0.91 ; \mathrm{P}<0.00001 ; \mathrm{I}^{2}=100 \%$ ) and migraine-specific medication days (MSMDs) from baseline (MD $-1.41 ; 95 \% \mathrm{Cl},-1.80$ to $-1.02 ; \mathrm{P} \otimes 0.00001$; $\mathrm{I}^{2}=100 \%$ ) were significantly increased for the erenumab group compared with placebo. Furthermore, there was significant reduction of MSMDs from baseline in $140 \mathrm{mg}$ erenumab group compared to $70 \mathrm{mg}\left(\mathrm{MD}=0.55 ; 95 \% \mathrm{Cl}: 0.54\right.$ to $\left.0.66 ; Z=10.95 ; P<0.00001 ; I^{2}=90 \%\right)$. Finally, there were no significant differences between erenumab group and placebo of any adverse events and serious adverse events.

Conclusion: Among patients with migraine, both 70mg and 140mg erenumab are associated with reduction of MMMDs, MSMDs from baseline and increased rate of $50 \%$ reduction without increased risk of any adverse events and serious adverse events.

\section{Background}

Approximately $30 \%$ of adults in the age group 18-65 suffer from headache disorders and about $30 \%$ of these individuals have migraine . Depending on the frequency of attacks, Migraine can be broadly classified as either episodic migraine(EM) (less than 15 days with headache per month) or chronic migraine(CM) (more than 15 days with headache per month), The third edition of the International Classification of Headache Disorders (ICHD3) published lately indicate that $\mathrm{CM}$, which singled out from types of EM, shares many features with, and can transform from EM. Symptoms of migraine, including pain, sensitivity to light, sound, and odors, vision changes (auras), nausea, vomiting, tingling/numbness, and language disturbances, pose significant disabling effects on sufferers' physical, social, and occupational functioning. Preventive treatments, such as topiramate, propranolol and valproate, $\beta$-blockers, and amitriptyline were not entirely effective and are commonly associated with side-effects, leading to negatively affecting treatment outcomes and poor adherence. Therefore, new, effective, safe, and tolerable preventive therapies were needed for patients who have failed existing treatment. Calcitonin generelated peptide (CGRP) is a 37-aminoacid neuropeptide that is involved in the pathophysiology of migraine through nociceptive modulation in the trigeminal vascular system. Several years ago, it was suggested that CGRP might be a valid target in the treatment of migraine. Many monoclonal antibodies developed to target CGRP as a preventive treatment of migraine has already shown its potential in the treatment of migraine. Erenumab, the only fully human monoclonal antibody and the most potent vasodilator peptide known , deserves special consideration.

Several randomized controlled trials (RCTs) have been conducted to investigate the effectiveness of erenumab in EM and CM. Therefore, we performed a meta-analysis of all RCTs comparing the efficacy and safety of erenumab of different doses to placebo and erenumab $70 \mathrm{mg}$ to $140 \mathrm{mg}$ in patients with migraine.

\section{Methods}

\section{Literature search and data source}

This meta-analysis is based on the Preferred Reporting Items for Systematic Reviews and Meta-Analyses Protocols (PRISMA-P) Statement 2015 . Two investigators (CZ and JG) independently and separately performed an electronic literature search using PubMed, Embase and Cochrane library from inception through October 28, 2018. A third independent researcher $(\mathrm{HX})$ resolved differences among researchers about inclusion of each trial. There are no language restrictions in our research. A combination of the variables of "Erenumab" were adopted as the search strategy for MEDLINE, EMBASE and Cochrane Library. Studies matching all text were searched. Moreover, relevant studies and previous meta-analysis references were reviewed to determine possible qualifications. Studies was initially screened in accordance with its title and summary to determine eligibility. The full text of the qualification study was assessed in the second step before exclusivity. The search process is shown in Fig. 1

\section{Study selection}

The following inclusion criteria were adopted to select trials:(1) RCTs about erenumab for migraine prevention; (2) At least one of the following outcomes is reported: MMMDs from baseline, $\geq 50 \%$ reduction from baseline in migraine days per month, MSMDs from baseline, adverse event and serious adverse events; (3) no limitations regarding the country, time, or language of publications. Exclusion criteria were as follows: (1) duration of follow-up was less than 7 days and duration of double-blind treatment phase was less than 3 months; (2) Erenumab observational trials to migraine. In order to assess risk of bias in RCTs, we used the Cochrane collaboration's tool to perform a quality assessment for the included RCTs. Risk of bias table including random sequence generation, allocation concealment, blinding of participants and personnel, blinding of outcome assessment, incomplete outcome data, selective reporting and other biases were used to assess all included RCTs (Table 1).

\section{Data extraction}

The data were independently and separately extracted by two reviewers (JG and HX) into a predesigned form from the included RCTs. A third investigator (CZ) will resolve disagreement. The information extracted from each study included lead author, participant characteristics, study design, sample size, outcomes, 
clinical follow-up, publication year and countries of origin.

\section{Outcomes}

The primary end point was the reduction of included $\geq 50 \%$ reduction from baseline in migraine days per month in different groups. The second end points were MMMDs from baseline and MSMDs from baseline. Safety outcomes were any or serious adverse events defined as per each included RCT.

\section{Statistical analysis}

The weighted mean differences (MDs) and 95\% confidence intervals (Cls) were reported by using the inverse variance (IV) test for continuous data. For dichotomous data, pooled risk ratios (RRs) and $95 \%$ Cls were cultivated by using the Mantel-Haenszel method. The Cochrane's Q statistics and I2 test were used to measure the heterogeneity in the study. The between-study heterogeneity was evaluated by a random-effects model. Sensitivity analysis was performed by excluding any single hazard ratio from the analysis. Visual inspection of the funnel plot was applied to assess publication bias. To evaluate the efficacy and safety of different dosage of erenumab against CGRP for migraine prevention, we also compared the efficacy and safety between 70 mg and 140mg erenumab. We used RevMan v5.3 Windows to analyze data. Statistically significant was judged only when $\mathrm{P}<0.05$.

\section{Results}

362 studies were revealed by a thorough literature search of electronic databases. After review, five RCTs that compared erenumab with placebo in patients with migraine were included. Detail of the selection process used for identifying the included RCTs are described in Fig.1. The summary characteristics of the included studies explained Table 2. Based on the quality assessment performed by the reviewers, all included studies have low risk of bias. There were 2,928 patients in total of all trials which were double-blinded. Different erenumab dosages were used in the included clinical trials; $70 \mathrm{mg}$ and $140 \mathrm{mg}$ every month were the most frequently used doses. Follow-up period are all 12 weeks. The baseline characteristics of the included patients are described in Table 3.

\section{Primary end point}

The subjects of our study include CM and EM patients, which leads to different baselines of MMMDs and MSMDs from one study to others . As a result, $\geq 50 \%$ reduction from baseline in migraine days per month, which is less effected by different baselines, was considered more appropriate to be the primary end point in weeks 9-12.

The outcomes of this meta-analysis indicated that the erenumab significantly increased the $\geq 50 \%$ reduction from baseline in migraine days per month, as compared with placebo group. (RR 1.55; $95 \% \mathrm{Cl}, 1.35$ to $1.77 ; \mathrm{P}<0.00001 ; I^{2}=49 \%$ ) (Fig. 2). Funnel plot did not suggest any significant publication bias (Fig 3 ), the heterogeneity may result from those groups were given different erenumab dosages.

Subgroup analysis indicated that 70mg (RR 1.54; $95 \% \mathrm{Cl}, 1.35$ to $1.75 ; \mathrm{P}<0.00001 ; \mathrm{I} 2=0 \%)$ and $140 \mathrm{mg}(\mathrm{RR}=1.86 ; 95 \% \mathrm{Cl}, 1.59$ to $2.19 ; \mathrm{P}<0.00001 ; \mathrm{I} 2=0 \%)$ for preventive treatment of migraine significantly increased the $\geq 50 \%$ reduction from baseline in migraine days per month, as compared with placebo group. There were no significant heterogeneities in both subgroups.

Analysis between $70 \mathrm{mg}$ and $140 \mathrm{mg}$ groups didn't show any difference in increasing $50 \%$ reduction from baseline in migraine days per month (RR $0.9,0.78$ to $1.03 ; P=0.12 ; 12=0 \%)$ (Fig.4).

\section{Secondary end points}

The secondary end point in weeks 9-12 included MMMDs from baseline and MSMDs from baseline at the 12th week.

\section{MMMDs from baseline}

Pooled analysis showed significant reductions in MMMDs from baseline in the erenumab group compared with the placebo group (MD $-1.32,95 \% \mathrm{Cl},-1.73$ to $\left.-0.91 ; \mathrm{P}<0.00001 ; \mathrm{I}^{2}=100 \%\right)$. Subgroup analysis implemented to assess the influence of different doses showed Erenumab $70 \mathrm{mg}$ (MD $-1.50,95 \% \mathrm{Cl}-1.93$ to $-1.07 ; \mathrm{P}<0.00001 ; \mathrm{I} 2=100 \%)$ and $140 \mathrm{mg}(\mathrm{MD}-1.97,95 \% \mathrm{Cl}-2.34$ to $-1.59 ; \mathrm{P}<0.00001 ; \mathrm{I} 2=99 \%)$ (Fig. 5) for preventive treatment of migraine compared with placebo group significantly reduced the MMMDs from baseline. There were significant heterogeneities in these results. Examination of the funnel plot did not suggest any publication bias (Fig. 6).

Sensitivity analysis by removing trials sequentially discovered that in subgroup 70mg erenumab vs placebo, after Goadsby (2017) and Tepper (2017) were removed, the heterogeneity in the subgroup reduced significantly $(P=1 ; 12=0 \%)$. It suggested that: 1$)$ As already mentioned, the patient enrolled were different between Tepper (2017) (enrolled CM patients) and other four articles (enrolled EM patients). The difference of baseline and reduced range in different researches may lead to heterogeneity. 2) The different way of categorization among groups in each study may lead to heterogeneity.

Analysis between $70 \mathrm{mg}$ and $140 \mathrm{mg}$ groups didn't show any difference in reduction of $\mathrm{MMMDs}$ from baseline(MD=0.25, $95 \% \mathrm{Cl},-0.24$ to $0.74 ; \mathrm{P}=0.31)(\mathrm{Fig} .7)$. There was also significant heterogeneity in the result (P凶0.00001, I2 =99\%), and the reasons of heterogeneity presumed are the same as those described above.

\section{MSMDs from baseline}

Merged analysis showed significant reductions in MSMDs from baseline in the erenumab group compared with the placebo group (MD $-1.41 ; 95 \% \mathrm{Cl},-1.80$ to $\left.-1.02 ; \mathrm{P} \otimes 0.00001 ; \mathrm{l}^{2}=100 \%\right)$.

Subgroup analysis indicated that compared with placebo group, erenumab 70mg (MD -1.13; $95 \% \mathrm{Cl},-1.58$ to $-0.69 ; \mathrm{P} \otimes 0.00001)$ and $140 \mathrm{mg}(\mathrm{MD}-1.63 ; 95 \% \mathrm{Cl}$, -2.23 to $-1.02 ; \mathrm{P}<0.00001$ ) (Fig. 8)for preventive treatment of migraine significantly reduced the MSMDs from baseline. There was significant heterogeneity in the results. The sensitivity analysis did not substantively alter the overall result, we still presume that the significant heterogeneity results from different 
standard of enrollment and distribution in each study. Because MSMDs from baseline are as sensitive as MMMDs from baseline and effected by different baselines and other factors.

Compared to $140 \mathrm{mg}$ Erenumab, 70mg significantly less reduced MSMDs from baseline (MD 0.55; $95 \% \mathrm{Cl}: 0.54$ to $0.66 ; \mathrm{P}<0.00001)$ (Fig. 9). There was significant heterogeneity in the result $(\mathrm{P}=0.002 ; 12=90 \%)$, which might result from the different standard of enrollment and distribution adopted in the two studies.

\section{Safety outcomes}

The safety outcomes in weeks 9-12 included any adverse events and serious adverse events. There were no significant differences between erenumab and placebo groups with regard to the risk of any adverse events (RR $0.97 ; 95 \% \mathrm{Cl}$ : 0.89 to $1.06 ; \mathrm{P}=0.49 ; \mathrm{I}=41 \%$ ) (Fig 10), Sensitivity analysis did not substantively alter the overall result. it infers that the standard of enrollment and distribution may contribute to the heterogeneity. Meanwhile, serious adverse events (RR 0.95; $95 \% \mathrm{Cl}: 0.57$ to $1.57 ; \mathrm{P}=0.84 ; \mathrm{I}=0 \%$ ) (Fig 11) has no significant differences between erenumab and placebo groups.

There were also no significant differences between $70 \mathrm{mg}$ and $140 \mathrm{mg}$ erenumab with regard to risk of any adverse events (RR $1.0 ; 95 \% \mathrm{Cl}: 0.89$ to $1.12 ; \mathrm{P}=$ $0.44 ; \mathrm{I}=0 \%$ ) (Fig 12) as well as serious adverse events (RR $1.76 ; 95 \% \mathrm{Cl}: 0.74$ to $4.17 ; \mathrm{P}=0.20 ; \mathrm{I}=0 \%$ ) (Fig 13).

\section{Discussion}

Our meta-analysis revealed some major findings as follows. First, both erenumab $70 \mathrm{mg}$ and $140 \mathrm{mg}$ dosage groups were associated with reduction of MMMDs and MSMDs from baseline at the 12th week when compared with placebo group. However, migraine patients gained no benefits when administrated erenumab $7 \mathrm{mg}$ and $21 \mathrm{mg}$ dosage compared with placebo. Second囚Compared with $70 \mathrm{mg}$ dosage groups, the effect of erenumab $140 \mathrm{mg}$ on migraine had no difference in reducing MMMDs, but had significant reduced MSMDs from baseline. Third, erenumab significantly increased $50 \%$ reduction from baseline when compared to placebo. The increased level has no difference between erenumab $70 \mathrm{mg}$ and $140 \mathrm{mg}$ dosage groups. Fourth, there were no significant differences between erenumab groups and placebo groups and between erenumab $70 \mathrm{mg}$ and $140 \mathrm{mg}$ dosage groups with regard to safety outcomes.

The efficacy of some monoclonal antibodies in migraine patients had been proved in many RCTs. Two systematic reviews reported that CGRP monoclonal antibody reduced the MMMDs from baseline, but did not consider multiple dosage groups of erenumab in each study. An antibody must have a long half-life and must be highly selective for the CGRP receptor. Erenumab is such an antibody with a favorable pharmacokinetic and pharmacodynamic profile, and one study had already described the development and pharmacological characteristics of erenumab. Subcutaneous injection (SC) formulation of erenumab was recently approved in the US for the prevention of migraine in adults. Phase I study indicated Single doses of erenumab has no apparent dose dependency for erenumab $\geq 21 \mathrm{mg}$. However, no research had seriously discussed the dosage of erenumab treatment to migraine patient. As a cost-effectiveness evaluation of erenumab for EM and CM from both the US societal and payer perspectives indicated, the use of 140mg erenumab may be a cost-effective approach to preventing MMMDs among patients with CM versus onabotulinumtoxinA and no preventive treatment in the societal and payer perspectives, but is less likely to offer good value for money for those with EM . Our meta-analysis indicate 140mg erenumab groups may bring more benefits than $70 \mathrm{mg}$ groups on reducing the MSMDs from baseline, which could weakly prove that $140 \mathrm{mg}$ erenumab may result in more benefits. As a new RCT had already shown, in patients whose previous treatments were unsuccessful, erenumab $70 \mathrm{mg}$ and $140 \mathrm{mg}$ were consistently more efficacious in terms of reduction in the mean number of migraine days than placebo, which indicate a greater clinical benefit for the erenumab $140 \mathrm{mg}$ dose than for the $70 \mathrm{mg}$ dose. However, limited by the sample size, heterogeneity result from different baselines and different grouping strategy in these five studies, more RCTs needs to be used to provide more effective evidence of whether $140 \mathrm{mg}$ erenumab displays more benefits than $70 \mathrm{mg}$.

\section{Limitations}

There are several limitations in the present meta-analysis. First, the inclusion criteria differed among the included studies. One study included CM patients while other studies included EM patients. The different standard of enrollment leads to different baseline in different research. Second, three of the included studies represented phase 3 trials, two were phase 2 trials. Third, erenumab was given in different doses across all included trials. Fourth, most of the patients enrolled were female, which may result from the fact that the epidemiology of migraine is two to three times more prevalent in women than men .

Our meta-analysis indicated erenumab could have preventive efficacy in patients with migraine without difference in safety outcome. Primarily discussion about how the dosage of erenumab effected on the outcome had been performed in our study, and the result can be a clue to researchers who consider the dosage of erenumab in their studies. In order to be more suggestive to the usage of erenumab, further adequately powered RCTs are needed to establish the best regimen specially for EM and $\mathrm{CM}$.

\section{Conclusions}

In patients with $\mathrm{EM}$ and $\mathrm{CM}, 70 \mathrm{mg}$ and $140 \mathrm{mg}$, erenumab are associated with improved MMMDs, MSMDs and with reduced rates of $50 \%$ reduction from baseline when compared to placebo. The reduction of MMMDs and $50 \%$ reduction from baseline between patients taking $70 \mathrm{mg}$ and $140 \mathrm{mg}$ erenumab, however, was not statistically significant in a subset of patients, despite the significant reduction of MSMDs from baseline in $140 \mathrm{mg}$ erenumab groups compared to $70 \mathrm{mg}$. Both $70 \mathrm{mg}$ and $140 \mathrm{mg}$ erenumab groups were not statistically significant different from placebo with regard to adverse events and serious events. Further adequately powered RCTs will be needed to establish the best erenumab dose to migraine. In addition, more studies should seek to evaluate the efficacy, safety and cost of erenumab in comparison with other available monoclonal antibodies.

\section{Declaration}




\section{Acknowledgements}

We thank all the participants for their support of this research.

\section{Funding}

This study and analyses were supported by The National Key Specialty Construction Project of Clinical Pharmacy $₫$ NO.30305030698ه.The funding paid staff costs for the design of the study and collection, and interpretation of data and in writing the manuscript.

\section{Availability of data and materials}

All data generated or analyzed during this study are included in this published article [and its Additional files].

Authors' contributions CZ, JG, HX, WL, and RT all made substantial contributions to the study conception and design; analysis and interpretation of data; and drafting and/or critically reviewing the manuscript. CZ, JG and HX was involved in acquisition of data. CZ, JG, HX, WL, and RT all reviewed and approved the final draft of the manuscript. CZ, JG, HX, WL, and RT all agreed to be accountable for all aspects of the work in ensuring that questions related to the accuracy or integrity of any part of the work are appropriately investigated and resolved.

\section{Ethics approval and consent to participate}

Not applicable.

\section{Consent for publication}

Not applicable.

\section{Competing interests}

The authors declare that they have no competing interests.

\section{References}

1. Jain S, Yuan H, Spare N, Silberstein SD. Erenumab in the treatment of migraine. Pain Manag 2018. doi:10.2217/pmt-2018-0037.

2. Lipton RB, Manack Adams A, Buse DC, Fanning KM, Reed ML. A Comparison of the Chronic Migraine Epidemiology and Outcomes (CaMEO) Study and American Migraine Prevalence and Prevention (AMPP) Study: Demographics and Headache-Related Disability. Headache. 2016;56:1280-9. doi:10.1111/head.12878.

3. Headache Classification Committee of the International Headache Society (IHS) The International Classification of Headache Disorders, 3rd edition. Cephalalgia. 2018;38:1-211. doi:10.1177/0333102417738202.

4. Katsarava Z, Buse DC, Manack AN, Lipton RB. Defining the Differences Between Episodic Migraine and Chronic Migraine. Curr Pain Headache Rep. 2012;16:86-92. doi:10.1007/s11916-011-0233-Z.

5. Lipton RB, Silberstein SD. Episodic and chronic migraine headache: breaking down barriers to optimal treatment and prevention. Headache. 2015;55 Suppl 2:103-22; quiz 123-6. doi:10.1111/head.12505_2.

6. Goadsby PJ, Edvinsson L, Ekman R. Vasoactive peptide release in the extracerebral circulation of humans during migraine headache. Ann Neurol 1990;28:183-7. doi:10.1002/ana.410280213.

7. Goadsby PJ, Edvinsson L. The trigeminovascular system and migraine: studies characterizing cerebrovascular and neuropeptide changes seen in humans and cats. Ann Neurol. 1993;33:48-56. doi:10.1002/ana.410330109.

8. Hansen JM, Hauge AW, Olesen J, Ashina M. Calcitonin gene-related peptide triggers migraine-like attacks in patients with migraine with aura. Cephalalgia. 2010;30:1179-86. doi:10.1177/0333102410368444.

9. Edvinsson L. Functional role of perivascular peptides in the control of cerebral circulation. Trends in Neurosciences. 1985;8:126-31. doi:10.1016/01662236(85)90050-5.

10. Russell FA, King R, Smillie S-J, Kodji X, Brain SD. Calcitonin gene-related peptide: physiology and pathophysiology. Physiol Rev. 2014;94:1099-142 doi:10.1152/physrev.00034.2013.

11. Moher D, Shamseer L, Clarke M, Ghersi D, Liberati A, Petticrew M, et al. Preferred reporting items for systematic review and meta-analysis protocols (PRISMA-P) 2015 statement. Syst Rev. 2015;4:1. doi:10.1186/2046-4053-4-1.

12. Reuter U, Goadsby PJ, Lanteri-Minet M, Wen S, Hours-Zesiger P, Ferrari MD, Klatt J. Efficacy and tolerability of erenumab in patients with episodic migraine in whom two-to-four previous preventive treatments were unsuccessful: a randomised, double-blind, placebo-controlled, phase $3 \mathrm{~b}$ study. The Lancet 2018. doi:10.1016/S0140-6736(18)32534-0. 
13. Dodick DW, Ashina M, Brandes JL, Kudrow D, Lanteri-Minet M, Osipova V, et al. ARISE: A Phase 3 randomized trial of erenumab for episodic migraine. Cephalalgia. 2018;38:1026-37. doi:10.1177/0333102418759786.

14. Goadsby PJ, Reuter U, Hallström Y, Broessner G, Bonner JH, Zhang F, et al. A Controlled Trial of Erenumab for Episodic Migraine. N Engl J Med. 2017;377:2123-32. doi:10.1056/NEJMoa1705848.

15. Sun H, Dodick DW, Silberstein S, Goadsby PJ, Reuter U, Ashina M, et al. Safety and efficacy of AMG 334 for prevention of episodic migraine: a randomised, double-blind, placebo-controlled, phase 2 trial. The Lancet Neurology. 2016;15:382-90. doi:10.1016/S1474-4422(16)00019-3.

16. Tepper S, Ashina M, Reuter U, Brandes JL, Doležil D, Silberstein S, et al. Safety and efficacy of erenumab for preventive treatment of chronic migraine: a randomised, double-blind, placebo-controlled phase 2 trial. The Lancet Neurology. 2017;16:425-34. doi:10.1016/S1474-4422(17)30083-2.

17. Mitsikostas DD, Reuter U. Calcitonin gene-related peptide monoclonal antibodies for migraine prevention: comparisons across randomized controlled studies. Curr Opin Neurol. 2017;30:272-80. doi:10.1097/WC0.0000000000000438.

18. Hong P, Wu X, Liu Y. Calcitonin gene-related peptide monoclonal antibody for preventive treatment of episodic migraine: A meta analysis. Clin Neurol Neurosurg. 2017;154:74-8. doi:10.1016/j.clineuro.2017.01.009.

19. Zhu Y, Liu Y, Zhao J, Han Q, Liu L, Shen X. The efficacy and safety of calcitonin gene-related peptide monoclonal antibody for episodic migraine: a metaanalysis. Neurol Sci 2018. doi:10.1007/s10072-018-3547-3.

20. Vu T, Ma P, Chen JS, Hoon J de, van Hecken A, Yan L, et al. Pharmacokinetic-Pharmacodynamic Relationship of Erenumab (AMG 334) and CapsaicinInduced Dermal Blood Flow in Healthy and Migraine Subjects. Pharm Res. 2017;34:1784-95. doi:10.1007/s11095-017-2183-6.

21. Shi L, Lehto SG, Zhu DXD, Sun H, Zhang J, Smith BP, et al. Pharmacologic Characterization of AMG 334, a Potent and Selective Human Monoclonal Antibody against the Calcitonin Gene-Related Peptide Receptor. J Pharmacol Exp Ther. 2016;356:223-31. doi:10.1124/jpet.115.227793.

22. Markham A. Erenumab: First Global Approval. Drugs. 2018;78:1157-61. doi:10.1007/s40265-018-0944-0.

23. Hoon J de, van Hecken A, Vandermeulen C, Yan L, Smith B, Chen JS, et al. Phase I, Randomized, Double-blind, Placebo-controlled, Single-dose, and Multiple-dose Studies of Erenumab in Healthy Subjects and Patients With Migraine. Clin Pharmacol Ther. 2018;103:815-25. doi:10.1002/cpt.799.

24. Sussman M, Benner J, Neumann P, Menzin J. Cost-effectiveness analysis of erenumab for the preventive treatment of episodic and chronic migraine: Results from the US societal and payer perspectives. Cephalalgia. 2018;38:1644-57. doi:10.1177/0333102418796842.

25. Vetvik KG, MacGregor EA. Sex differences in the epidemiology, clinical features, and pathophysiology of migraine. Lancet Neurol. 2017;16:76-87. doi:10.1016/S1474-4422(16)30293-9.

\section{Tables}

Table 1. Assessment of the methodological aspects of the included studies

\begin{tabular}{|c|c|c|c|c|c|c|c|c|c|c|}
\hline \multicolumn{2}{|c|}{ First author and year } & m sequence generation Allo & cation conc & ealment & Blinding & Incomplete outcome data & Selective outcome repc & rting & Other so & arces of bi \\
\hline \multicolumn{2}{|c|}{ Goadsby (2017) } & low risk & \multicolumn{2}{|c|}{ low risk } & low risk & low risk & \multicolumn{2}{|c|}{ low risk } & \multicolumn{2}{|c|}{ unclear risk } \\
\hline \multicolumn{2}{|c|}{ Dodick $\square 2018 \square$} & low risk & \multicolumn{2}{|l|}{ low risk } & low risk & low risk & \multicolumn{2}{|l|}{ low risk } & \multicolumn{2}{|c|}{ unclear risk } \\
\hline \multicolumn{2}{|c|}{$\operatorname{Sun} \llbracket 2016 \square$} & low risk & \multicolumn{2}{|l|}{ low risk } & low risk & low risk & low risk & & \multicolumn{2}{|c|}{ unclear risk } \\
\hline \multicolumn{2}{|c|}{ Goadsby $\llbracket 2018 \square$} & low risk & \multicolumn{2}{|l|}{ low risk } & low risk & low risk & low risk & & \multicolumn{2}{|c|}{ unclear risk } \\
\hline Goadsby (2017) & NCT02456740 & $\begin{array}{l}\text { multicenter, double-blind,phase } \\
3 \text { trial 1:1:1 randomization }\end{array}$ & 12 weeks & \multicolumn{4}{|c|}{$\begin{array}{l}\text { Adults (18 to } 65 \text { years old), history of migraine } \$>12 \text { months, headach days } / \text { month } \\
115 \text { on average during the } 3 \text {-month period before screening }\end{array}$} & \multicolumn{2}{|c|}{$\begin{array}{l}70 \mathrm{mg} \text { or } 140 \\
\text { mg monthly }\end{array}$} & 955 \\
\hline Dodick $\square 2018 \square$ & NCT02483585 & $\begin{array}{l}\text { multicenter, double-blind,phase } \\
3 \text { trial 1:1 randomization }\end{array}$ & 12 weeks & \multicolumn{4}{|c|}{$\begin{array}{l}\text { Adults ( } 18 \text { to } 65 \text { years old) with a history of episodic migraine }>12 \text { months with or } \\
\text { without aura }\end{array}$} & \multicolumn{2}{|c|}{70 mg monthly } & 577 \\
\hline Sun $\square 2016 \square$ & NCT01952574 & $\begin{array}{l}\text { multicenter, double-blind,phase } \\
2 \text { trial } 3: 2: 2: 2 \text { randomization }\end{array}$ & 12 weeks & \multicolumn{4}{|c|}{ Adults (18 to 60 years old) with a history of episodic migraine } & \multicolumn{2}{|c|}{70 mg monthly } & 483 \\
\hline Tepper $2017 \square$ & NCT02066415 & $\begin{array}{l}\text { multicenter, double-blind,phase } \\
2 \text { trial 3:2:2 randomization }\end{array}$ & 12 weeks & \multicolumn{4}{|c|}{$\begin{array}{l}\text { Adults ( } 18 \text { to } 65 \text { years old) with a history of chronic migraine with or without aura } \\
\text { were enrolled. }\end{array}$} & \multicolumn{2}{|c|}{$\begin{array}{l}70 \mathrm{mg} \text {, or } 140 \\
\text { mg monthly }\end{array}$} & 667 \\
\hline Reuter $22018 \square$ & NCT03096834 & $\begin{array}{l}\text { double-blind,phase } 3 \text { trial } 1: 1 \\
\text { randomization }\end{array}$ & 12 weeks & \multicolumn{4}{|c|}{$\begin{array}{l}\text { Adults ( } 18 \text { to } 65 \text { years old) with a history of migraine symptoms in the } 12 \text { months } \\
\text { before screen. Failure of previous migraine prophylactic treatments }\end{array}$} & \multicolumn{2}{|c|}{$\begin{array}{l}140 \mathrm{mg} \\
\text { monthly }\end{array}$} & 246 \\
\hline
\end{tabular}

Table 3. Baseline characteristics of study population reported for overall population in each study 


\begin{tabular}{|c|c|c|c|c|c|c|c|c|c|c|c|c|}
\hline & \multicolumn{4}{|c|}{ Sun $\square 2016 \square$} & \multicolumn{3}{|c|}{ Goadsby (2017) } & \multicolumn{3}{|c|}{ Tepperป20170 } & \multicolumn{2}{|c|}{ Dodick $\square 2018$} \\
\hline & placebo & $\begin{array}{c}\text { Erenumab } \\
\text { 07mg }\end{array}$ & $\begin{array}{c}\text { Erenumab } \\
021 \mathrm{mg}\end{array}$ & $\begin{array}{c}\text { Erenumab } \\
\square 70 \mathrm{mg} \square\end{array}$ & placebo & $\begin{array}{c}\text { Erenumab } \\
070 \mathrm{mg}\end{array}$ & $\begin{array}{c}\text { Erenumab } \\
1140 \mathrm{mg}\end{array}$ & placebo & $\begin{array}{c}\text { Erenumab } \\
\square 70 \mathrm{mg} \square\end{array}$ & $\begin{array}{c}\text { Erenumab } \\
\square 140 \mathrm{mg}\end{array}$ & placebo & $\begin{array}{r}\text { Eren } \\
070\end{array}$ \\
\hline Total patient's number & 160 & 108 & 108 & 107 & 319 & 317 & 319 & 286 & 191 & 190 & 291 & 2 \\
\hline Age mean $\pm \mathrm{SD}$ & $41 \cdot 4 \pm 10 \cdot 0$ & $40 \cdot 3 \pm 10 \cdot 9$ & $39 \cdot 9 \pm 12 \cdot 3$ & $42 \cdot 6 \pm 9 \cdot 9$ & $41.3 \pm 11.2$ & $41.1 \pm 11.3$ & $40.4 \pm 11.1$ & $42 \cdot 1 \pm 11 \cdot 3$ & $41 \cdot 4 \pm 11 \cdot 3$ & $42 \cdot 9 \pm 11 \cdot 1$ & $42 \pm 12$ & 42: \\
\hline Female No. (\%) & $132(83)$ & $88(81)$ & $87(81)$ & $82(77)$ & 274 (85.9) & $268(84.5)$ & $272(85.3)$ & $226(79)$ & $166(87)$ & $160(84)$ & 247 (84.9) & 2451 \\
\hline MMMDs mean \pm SD & $8 \cdot 8 \pm 2 \cdot 7$ & $8 \cdot 6 \pm 2 \cdot 8$ & $8 \cdot 9 \pm 2 \cdot 9$ & $8 \cdot 6 \pm 2 \cdot 5$ & $8.2 \pm 2.5$ & $8.3 \pm 2.5$ & $8.3 \pm 2.5$ & $18 \cdot 2 \pm 4 \cdot 7$ & $17 \cdot 9 \pm 4 \cdot 4$ & $17 \cdot 8 \pm 4 \cdot 7$ & $8.4 \pm 2.6$ & 8.1: \\
\hline MSMDs mean \pm SD & & & & & $3.4 \pm 3.4$ & $3.2 \pm 3.4$ & $3.4 \pm 3.5$ & $9 \cdot 5 \pm 7 \cdot 6$ & $8 \cdot 8 \pm 7 \cdot 2$ & $9 \cdot 7 \pm 7 \cdot 0$ & $3.4 \pm 3.6$ & 3.7: \\
\hline Monthly headache days $\mathrm{m}$ & $\pm \mathrm{SD}$ & & & & $9.3 \pm 2.6$ & $9.1 \pm 2.6$ & 21. & $20 \cdot 5$ & $20 \cdot 7 \pm 3 \cdot 8$ & $9.3 \pm 2.7$ & $9.1 \pm 2.7$ & $\overline{1 c}$ \\
\hline
\end{tabular}

\section{Figures}

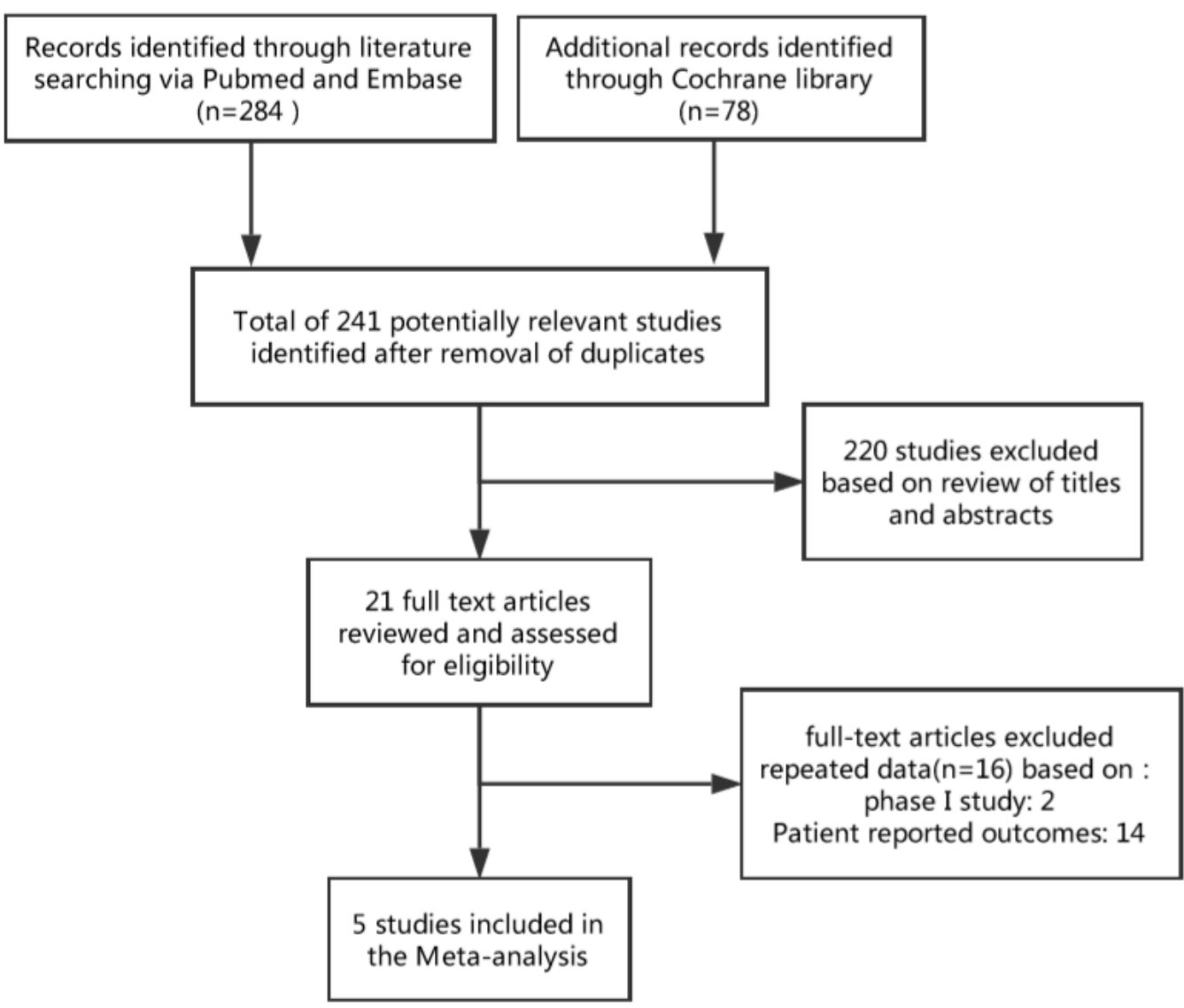

Figure 1 


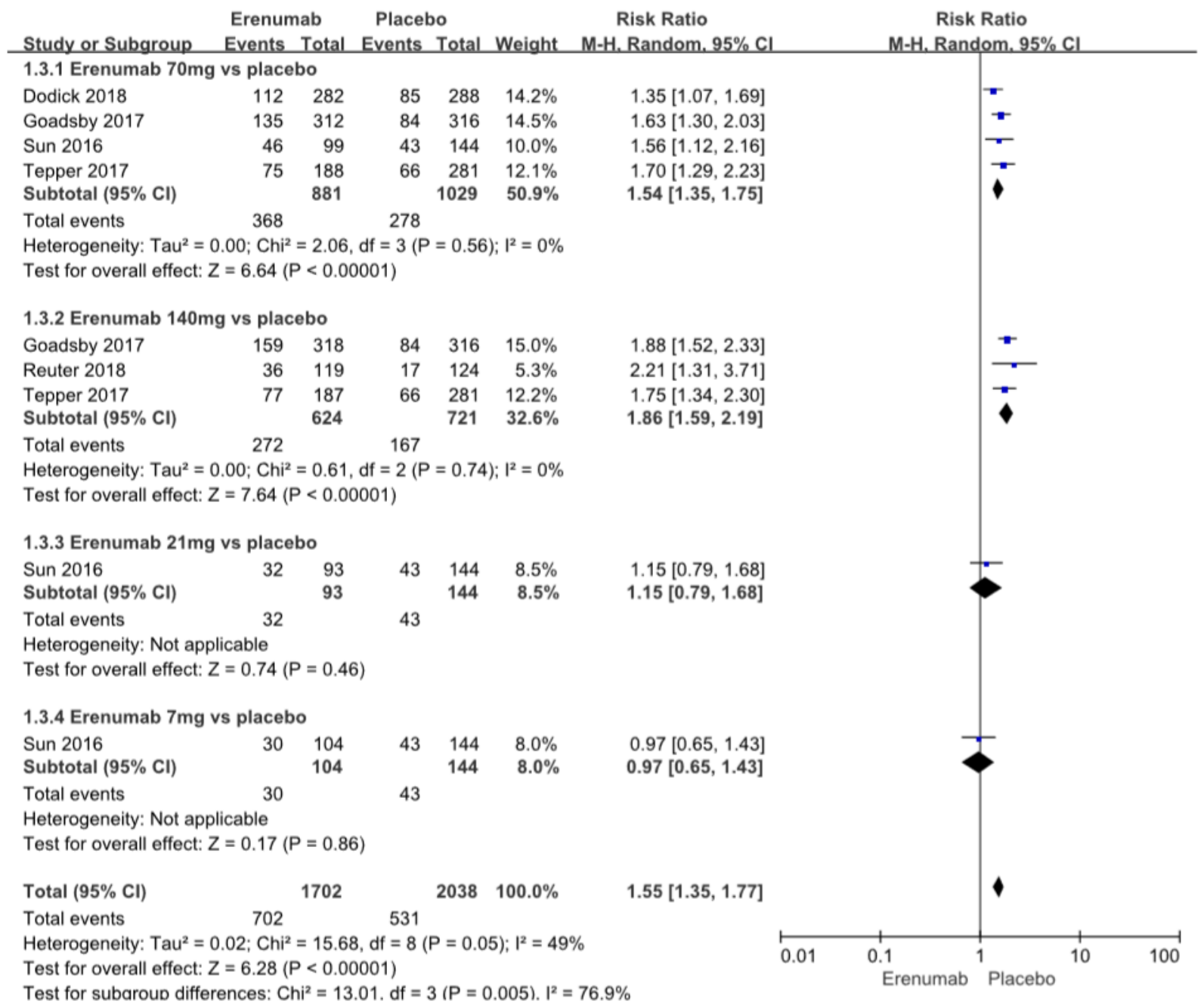

Figure 2 


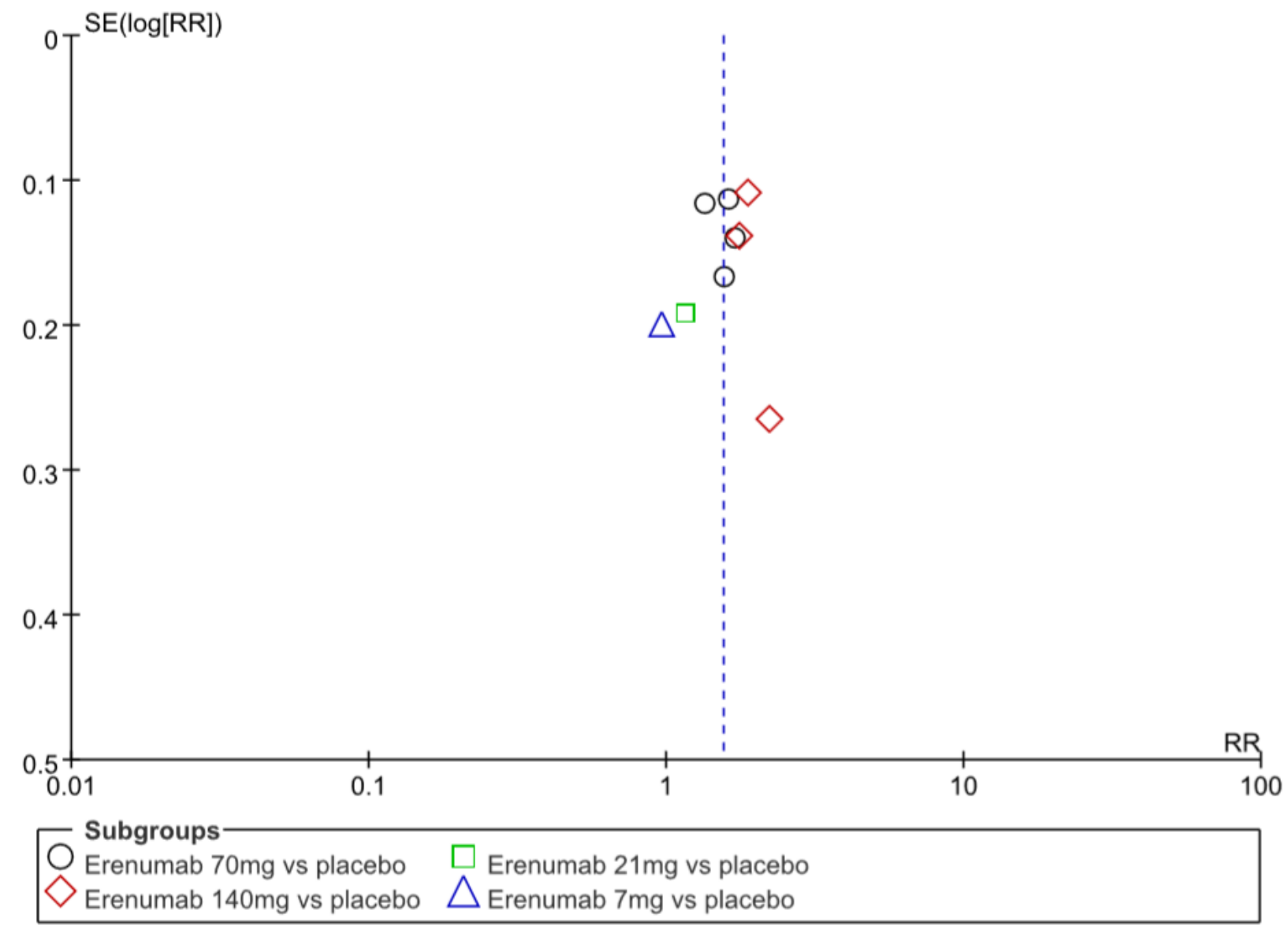

Figure 3 

Erenumab
Placebo
Risk Ratio
Risk Ratio

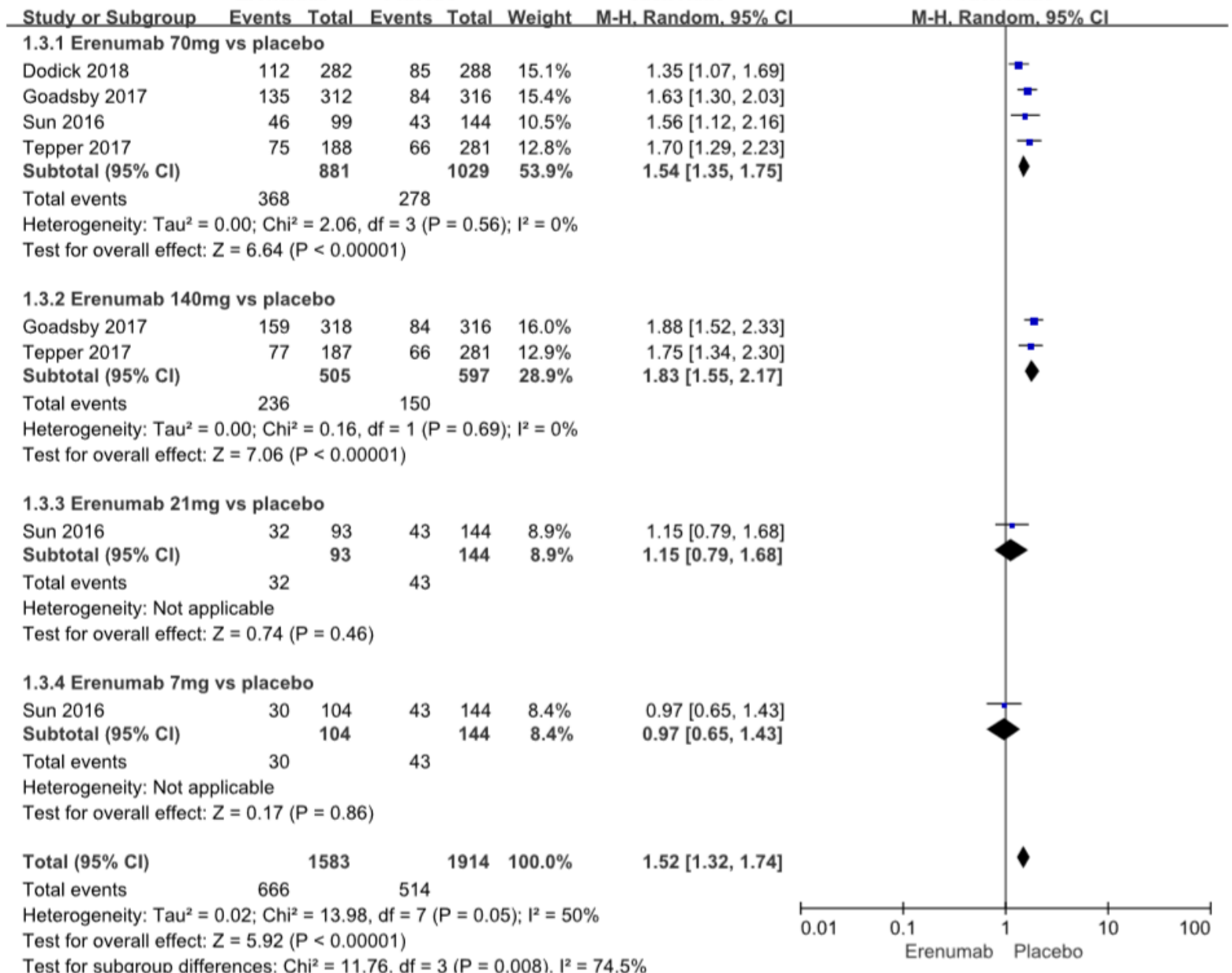

\section{Figure 4}




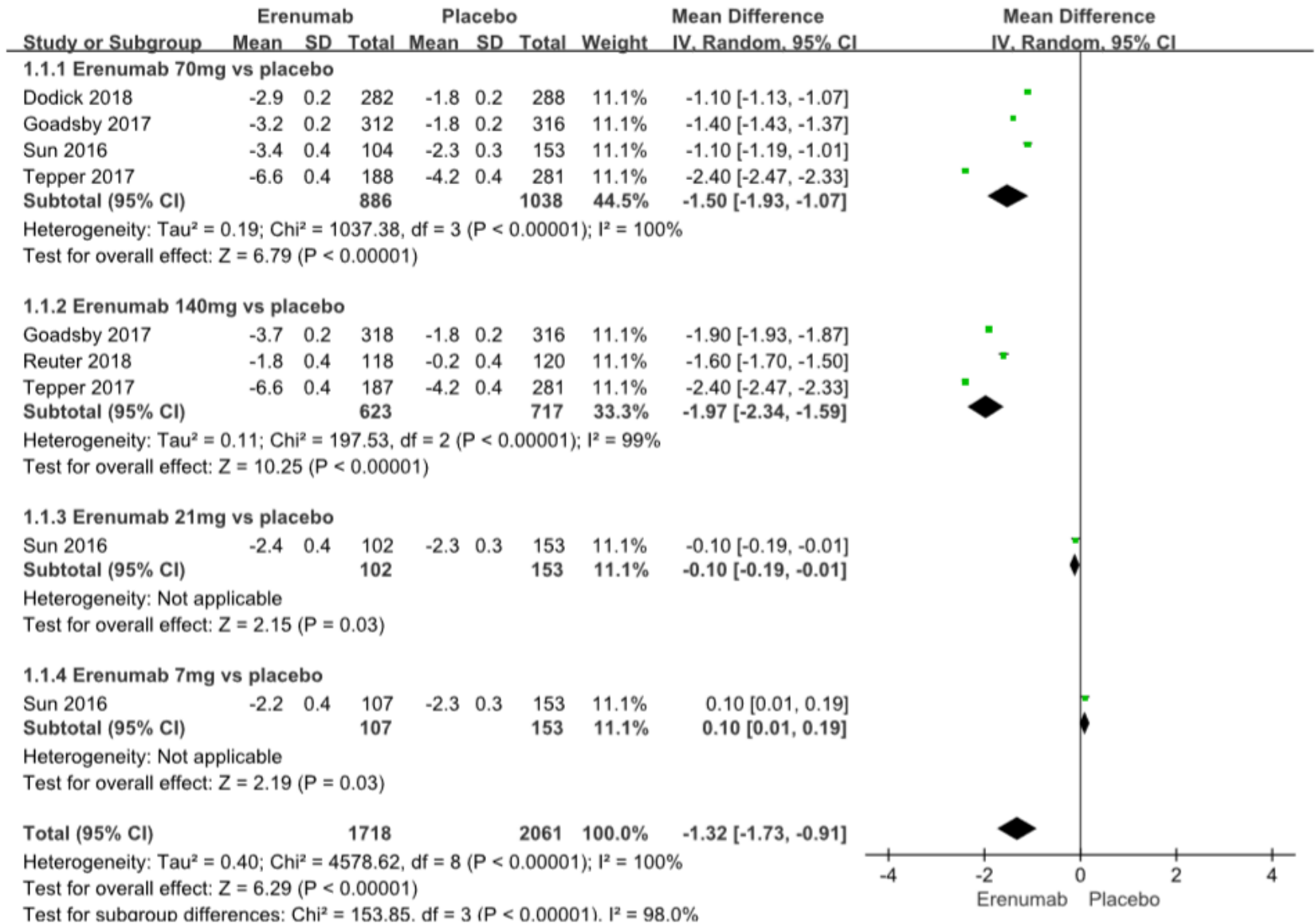

Figure 5 


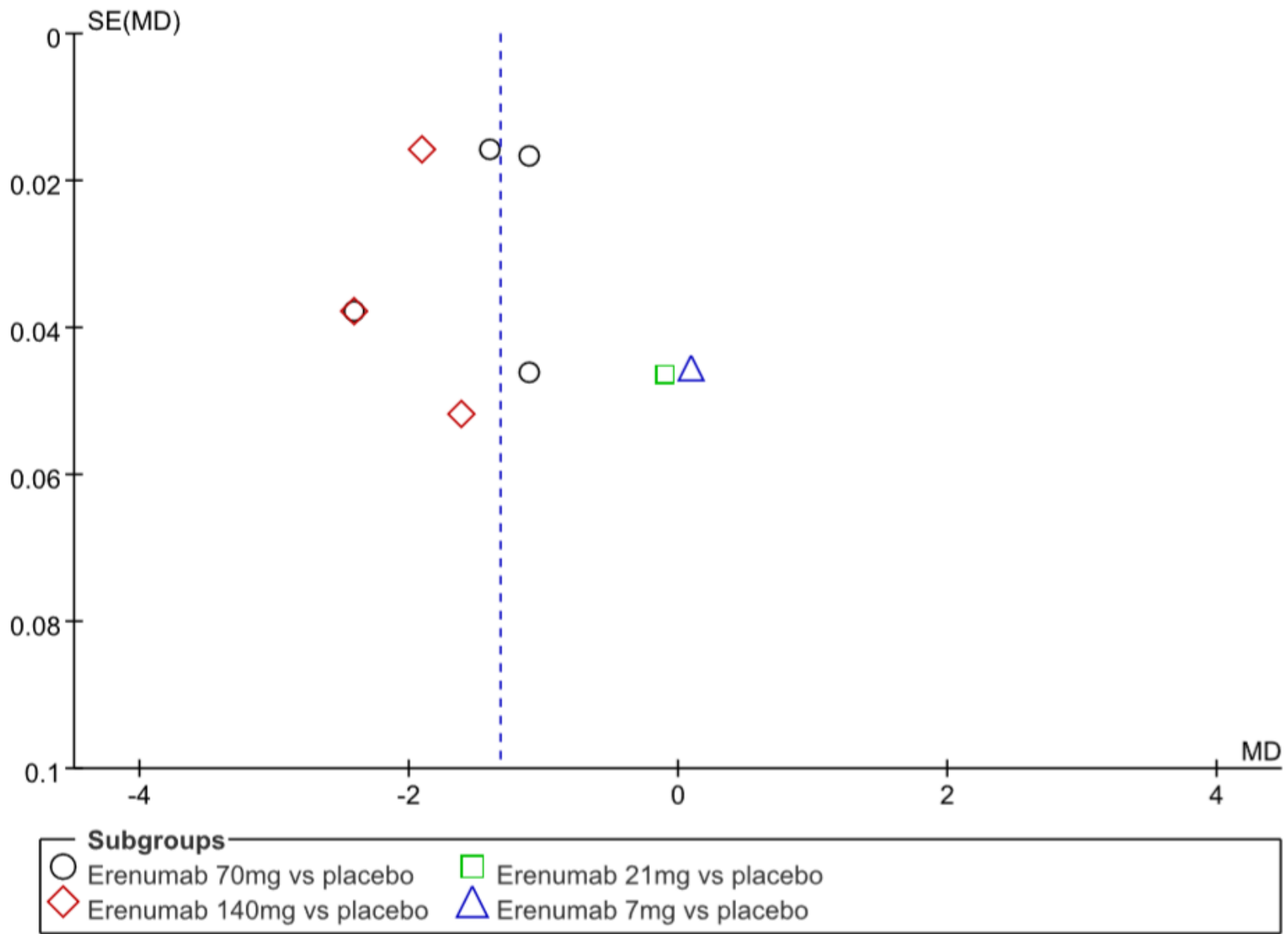

Figure 6

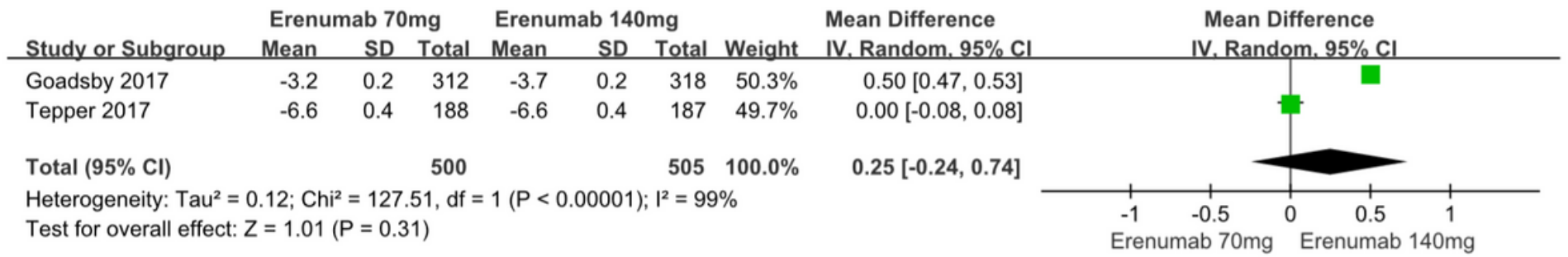

Figure 7 


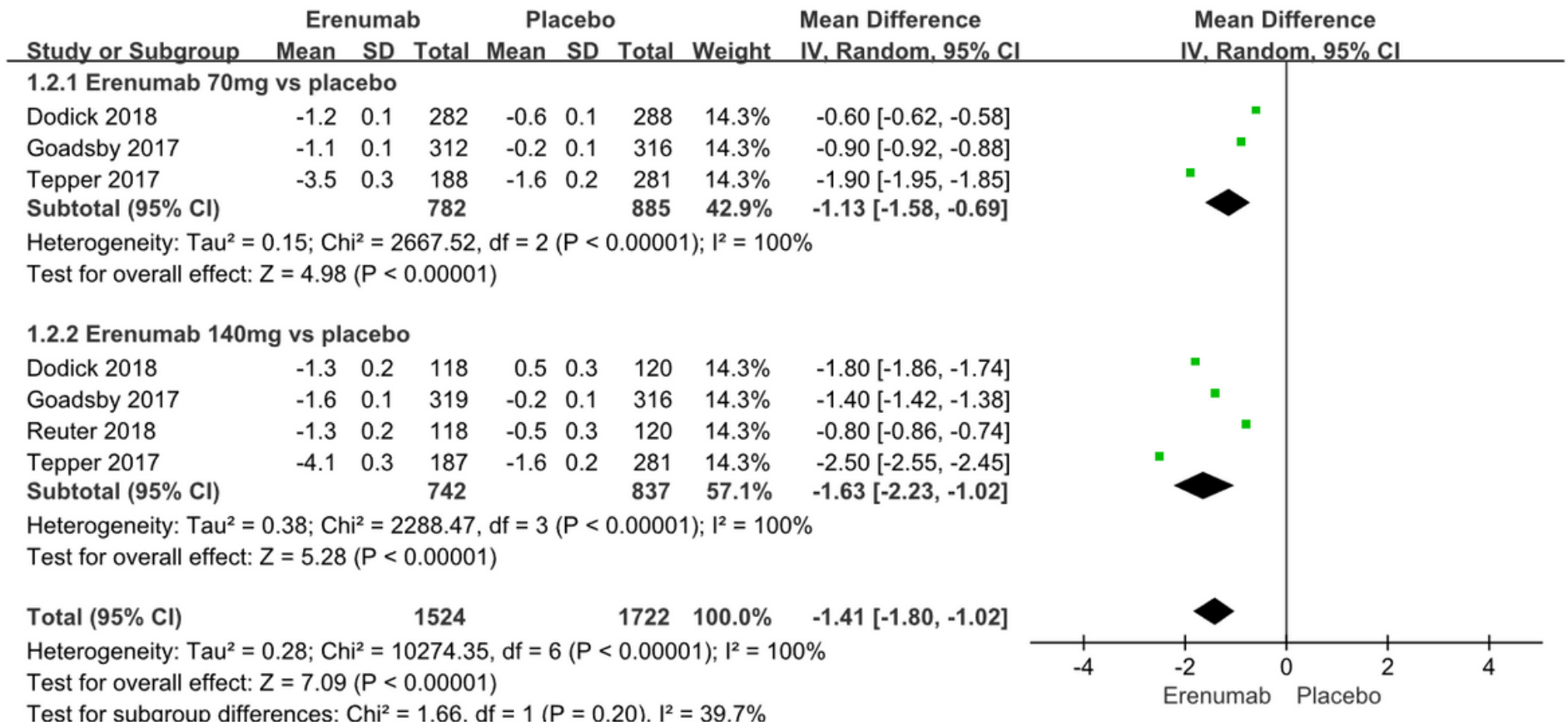

Figure 8

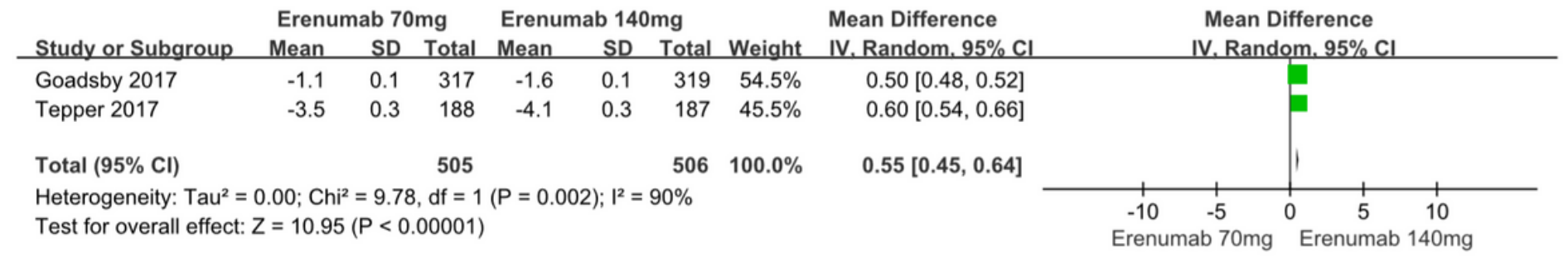

Figure 9 
Erenumab Placebo Risk Ratio

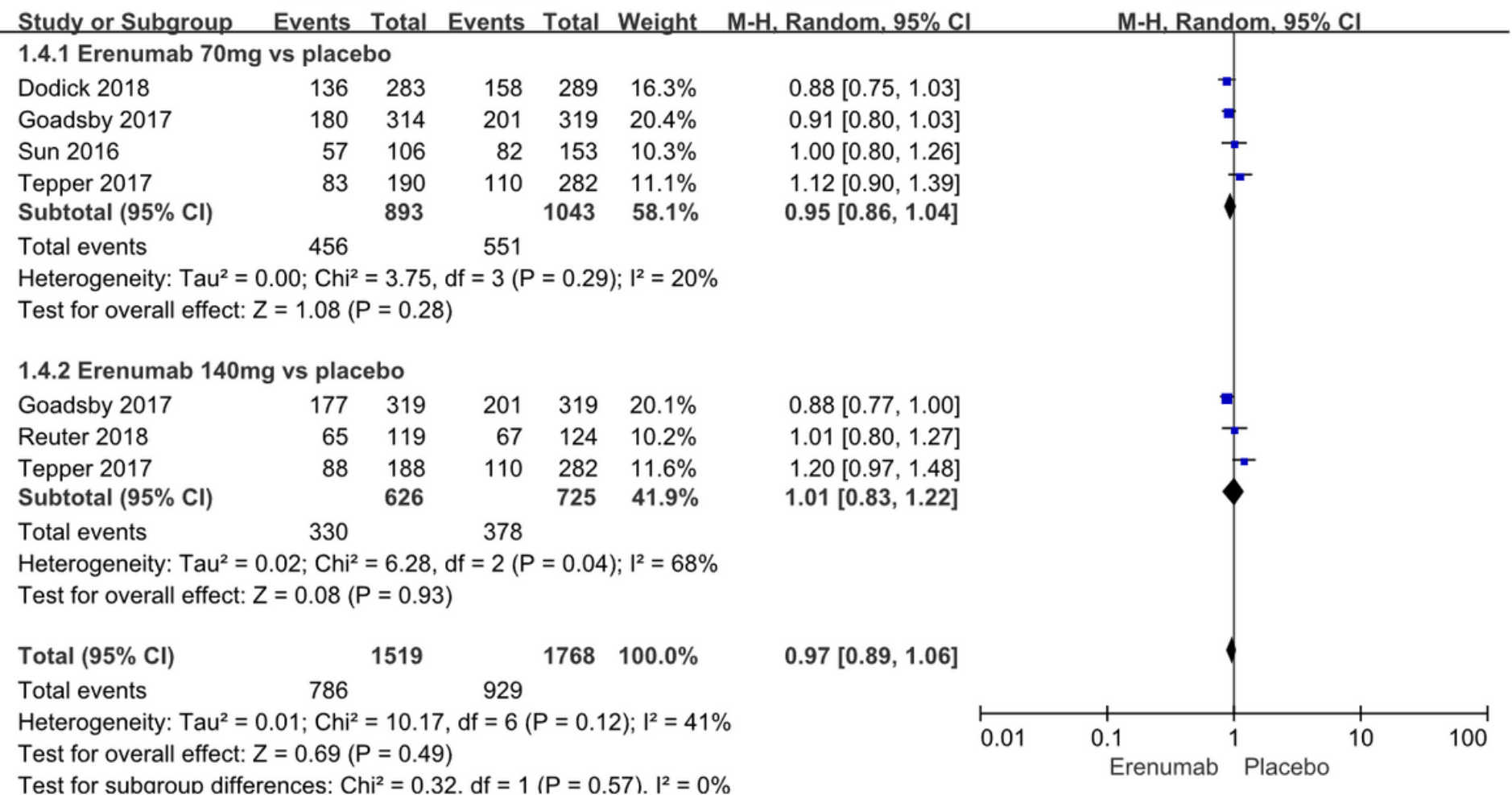

\section{Figure 10}

\begin{tabular}{|c|c|c|c|c|c|c|c|c|c|c|c|}
\hline \multirow[b]{2}{*}{ Study or Subgroup } & \multicolumn{2}{|c|}{ Erenumab $70 \mathrm{mg}$} & \multicolumn{2}{|c|}{ Erenumab $140 \mathrm{mg}$} & \multicolumn{3}{|c|}{ Risk Ratio } & \multirow{2}{*}{\multicolumn{2}{|c|}{$\begin{array}{c}\text { Risk Ratio } \\
\mathrm{M}-\mathrm{H} . \text { Random. } 95 \% \mathrm{Cl}\end{array}$}} & & \\
\hline & Events & Total & Events & Total & Weight & M-H. Random. $95 \% \mathrm{Cl}$ & & & & & \\
\hline Goadsby 2017 & 180 & 314 & 177 & 319 & $72.4 \%$ & $1.03[0.90,1.18]$ & & & & & \\
\hline Tepper 2017 & 83 & 190 & 88 & 188 & $27.6 \%$ & $0.93[0.75,1.17]$ & & & & & \\
\hline Total $(95 \% \mathrm{Cl})$ & & 504 & & 507 & $100.0 \%$ & $1.00[0.89,1.13]$ & & & $>$ & & \\
\hline Total events & 263 & & 265 & & & & & & & & \\
\hline $\begin{array}{l}\text { Heterogeneity: } \mathrm{Tau}^{2}= \\
\text { Test for overall effect: }\end{array}$ & $\begin{array}{l}0.00 ; \mathrm{Chi}^{2}= \\
Z=0.08(P\end{array}$ & $\begin{array}{l}59, \mathrm{df}= \\
.94)\end{array}$ & $1(P=0.44$ & $=0 \%$ & & & 0.01 & $\begin{array}{l}0.1 \\
\text { Erenumab 70mg }\end{array}$ & $\begin{array}{l}10 \\
\text { Erenumab } 10\end{array}$ & $\begin{array}{l}0 \\
140 \mathrm{mg}\end{array}$ & 100 \\
\hline
\end{tabular}

Figure 11 


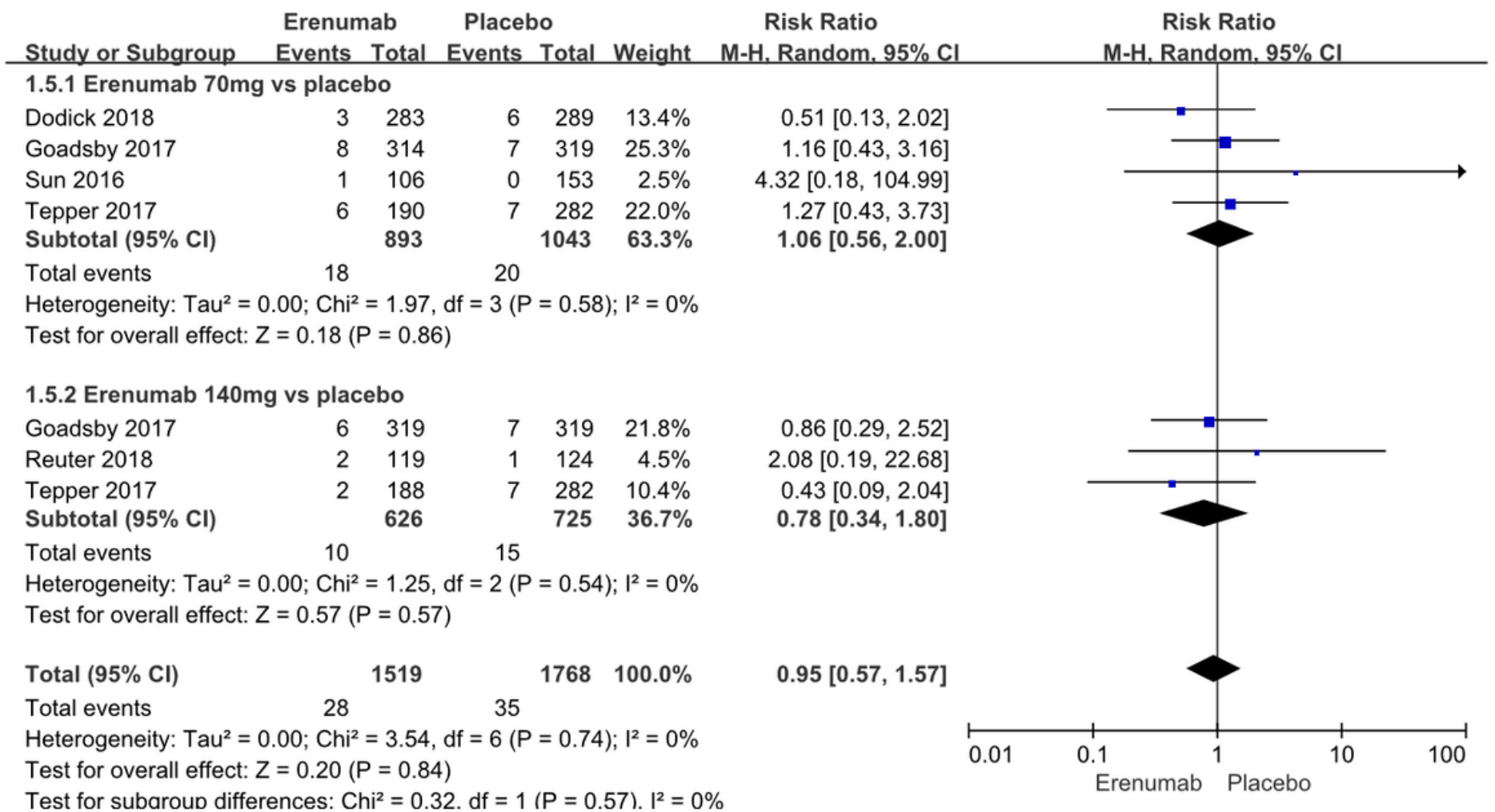

\section{Figure 12}

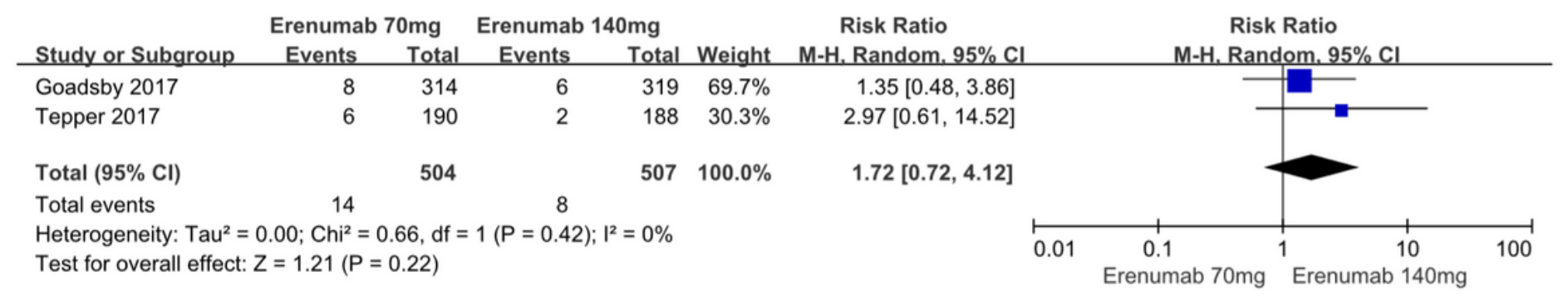

Figure 13

\section{Supplementary Files}

This is a list of supplementary files associated with this preprint. Click to download.

- supplement1.docx 